\title{
E-Marketing Audit sebagai Tools Pengendalian Usaha pada UKM di Kota Malang
}

\author{
Resanti Lestari $^{1^{*}}$, Rudy Wahyono ${ }^{2}$, Aris Siswati ${ }^{3}$ \\ 1,2 Program Studi Manajemen, Fakultas Ekonomi dan Bisnis, Universitas Merdeka Malang, \\ Malang, Indonesia \\ ${ }^{3}$ Program Studi Ekonomi Pembangunan, Fakultas Ekonomi dan Bisnis, Universitas Merdeka \\ Malang, Malang, Indonesia \\ *resanti.lestari@gmail.com
}

\begin{abstract}
This study aims to: 1) design an information system related to marketing audits, especially marketing functions in the form of an E-Marketing Audit model design based on conceptual studies and empirical exploration, 2) develop a web-based information system, and 3) apply the E-Marketing Audit model for SMEs Malang City. This study uses a qualitative research methods. Qualitative research is conducted to define the need for marketing audits using depth in interviews to enrich the development of conceptual models and applicable systems. While system development uses the waterfall SDLC model development method. This method is a sequential or sequential approach to the software life flow starting from analysis, design, coding, testing and implementation. The object of research is an SME in Malang City, observation activities are conducted on 20 SMEs in Malang City and depth interview is conducted with 3 SMEs who represent the characteristics needed in this research. This activity is aimed at elaborating on the need for the formation of a model as a basis for designing an applicable model of E-Marketing audit for SMEs in Malang. The results obtained are in the form of a web-based marketing audit system that is ready to be used by prospective users (SMEs). The resulting marketing audit system features recording product sales, recording of production costs and product price variations, recording sales channels (if an SME uses more than 1 distribution channel), auditing promotional activities by connecting the system to social media and measuring its impact.
\end{abstract}

Keywords: Marketing Audit, SMEs

\section{PENDAHULUAN}

Kewirausahaan merupakan salah satu faktor pendorong untuk meningkatkan pembangunan ekonomi di Indonesia. Perusahaan-perusahaan kecil dan menengah menyerap banyak tenaga kerja serta dapat membantu memberikan kesejahteraan bagi masyarakat kecil ditengah keadaan perekonomian yang masih belum stabil di masa pandemi Covid-19. Dukungan terhadap pengembangan Usaha Kecil Menengah agar memiliki daya saing lebih tinggi dan lebih melek teknologi merupakan tugas bersama. Wirda et al. (2019) menyatakan bahwa keunggulan bersaing UKM dihasilkan dari entrepreneural competency dan business performance. Kajian Aureli dan Del Baldo (2016) menyatakan bahwa pengukuran kinerja UKM masih belum banyak dilakukan karena pengukuran kinerja dianggap terlalu 
kompleks, mahal, diperlukan birokrasi dalam pelaksanaannya dan berbagai keterbatasan yang dimiliki UKM.

Urgensi mengenai pengukuran kinerja UKM juga banyak diutarakan oleh para ahli (Farneti \& Bartolini, 2009; Lombardi et al., 2015; Corsi, 2006). Pontoh dan Budiarso (2020) menyatakan bahwa UKM dapat meningkatkan daya saingnya melalui pemanfaatan teknologi informasi. Salah satu cara membantu UKM agar memiliki daya saing lebih tinggi dengan mendorong UKM agar melek IT melalui marketing audit.

Marketing audit pertama dikenal dalam literatur pemasaran adalah di akhir 1950an, yaitu oleh Scuhman dalam AMA. Kajian ini diangkat kembali oleh Kotler et al. (1977) yang mulai mengkaji pengembangan marketing audit dalam sebuah perusahaan. Kotler, et al (1977) juga mulai merumuskan pertanyaan-pertanyaan yang perlu dijadikan umpan balik bagi perusahaan, adapun bentuk dari marketing audit dapat berupa kuesioner terstruktur dengan tujuan menguji seberapa baik perusahaan atau bagaimana performa perusahaan selama ini.

Salah satu definisi dari marketing audit dirumuskan oleh Kotler dan Amstrong (2010) yang menyatakan bahwa marketing audit is a comprehensive, systematic, independent and periodic examination of the environment, objectives, strategies and activities of the company, which aims to identify problem areas and opportunities and recommendations for further action to streamline marketing company.

Beberapa peneliti juga memberikan kontribusinya dan mulai mengkaji pentingnya marketing audit, diantaranya adalah Brownlie (1996a) yang menyatakan bahwa marketing audit merupakan suatu instrumen dalam rangka menghadapi perubahan. Brownlie (1996) juga menyarankan bahwa marketing audit merupakan bagian penting dari proses perencanaan pemasaran.

Gibbs dan Knapp (2002) menyatakan bahwa marketing audit is a way to to investigate the realism and purposefulness of your marketing and management information systems. Lebih lanjut Gibbs dan Knapp (2002) menyatakan bahwa marketing audit memberikan pandangan secara langsung mengenai hubungan perusahaan dengan pasar baik secara internal maupun eksternal. Audit pemasaran secara berkala perlu dilakukan untuk memastikan apakah upaya-upaya yang telah dilakukan perusahaan telah sesuai dan sejalan dengan apa yang telah direncanakan dan selaras dengan tujuan perusahaan. Audit pemasaran dapat dilakukan sendiri (self assessment) ataupun menggunakan jasa konsultan.

Kajian lain mengenai marketing audit dilakukan oleh Taghian dan Shaw (2008) yang mencoba untuk memperkenalkan audit pemasaran karena selama ini yang banyak dikenal oleh khalayak adalah audit keuangan, audit lingkungan dan audit Sumber Daya Manusia (SDM). Mereka menjelaskan bahwa pertumbuhan suatu perusahaaan sangat terkait dengan marketing audit. Temuannya menunjukkan bahwa marketing audit dapat meningkatkan keefektifan praktek pemasaran.

Klinčeková dan Šalgovičová (2014) merumuskan 6 komponen utama dari marketing audit yaitu : Audit of marketing environment, Audit of marketing strategy, Audit of marketing organizations, Audit of marketing systems, Audit of marketing productivity, dan yang terakhir adalah Audit of marketing functions yang merupakan bentuk evaluasi pada setiap detail-detail secara terpisah dari marketing mix. Sedangkan Metode dari marketing audit menurut Klinčeková dan Šalgovičová (2014) terdapat tiga cara yaitu : 1) Self audit; 2) Audit realized by another manager; 3) Utilizing of external experts. Sistem marketing audit yang kami kembangkan ini merupakan bentuk dari metoda self audit, dimana perusahaan dapat melakukan audit pemasaran secara mandiri menggunakan data data yang tersistem. Dengan bantuan sistem dan data data terpadu, maka pemilik usaha dapat dengan mudah melakukan cek dan ricek kegiatan pemasaran usahanya.

Lebih lanjut Klinčeková dan Šalgovičová (2014) mengemukakan bahwa untuk melakukan audit pemasaran, maka 
terdapat terdapat 6 proses tahapan. Adapun tahapan tersebut dapat dilihat pada Gambar 1.

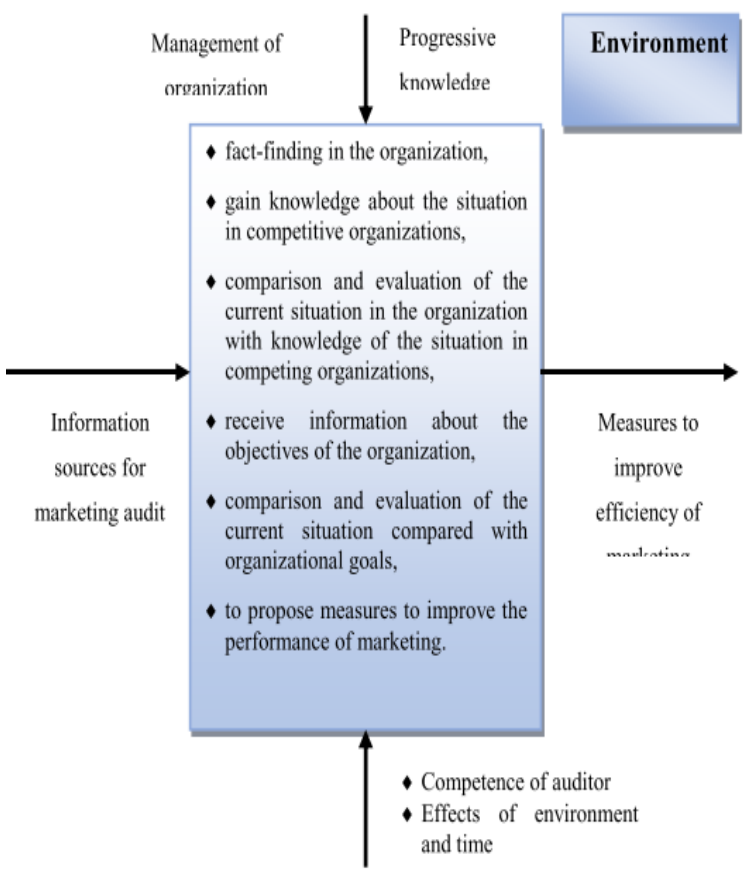

Gambar 1. Proses Marketing Audit Sumber: Klinčeková \& Šalgovičová (2014)

Keseluruhan pakar pemasaran di atas menyetujui bahwa marketing audit merupakan suatu instrumen yang digunakan untuk menilai keseluruhan kinerja organisasi dan sebagai tolak ukur pada strategi pemasaran yang telah ditentukan. Namun, kajian pengukuran performa bisnis pada UKM masih belum banyak dilakukan, pengukuran performa bisnis banyak dilakukan oleh perusahaan yang sudah besar dan mature dalam pasar dan persaingan usaha.

Kajian ini mencoba memperkaya temuan bahwa pengukuran performa bisnis menggunakan marketing audit dapat membantu peningkatan daya saing usaha UKM. Selanjutnya dikembangkan suatu model aplikatif dari marketing audit yang disesuaikan dengan kebutuhan sektor UKM. Konstruk model diadopsi dari beberapa model peneliti lain (Bolisani \& Scarso, 2012; Hasibuan, 2015; Lestari \& Prihartono AH, 2016; Öztamur \& Karakadılar, 2014; Yamani et al., 2019) serta pengembangan sistem.

Pengembangan sistem ini dianggap penting karena urgensi dari teknologi dalam aktivitas bisnis saat ini semakin meningkat. Pengembangan sistem pengukuran pemasaran berbasis teknologi ini bagi perusahaan menengah ataupun besar kemungkinan telah dikembangkan serta dipastikan perusahaan perusahaan besar telah memiliki sistem terintegrasi untuk melakukan pengukuran tersebut, namun untuk sektor UKM penggunaan teknologi dalam rangka pengukuran atau audit pemasaran ini belum banyak digunakan. Berdasarkan hal tersebut, maka penelitian ini diharapkan dapat memperkaya dari sisi konseptual maupun memiliki urgensi dalam hal praktis.

\section{METODE}

Penelitian ini peneliti menggunakan metode mixed method. Penelitian kualitatif digunakan pada tahap awal penelitian, metode ini dilakukan pada saat penggalian dan elaborasi keperluan data pengembangan sistem. Terdapat 2 tahapan dalam penelitian ini yaitu: 1) Pendefinisian kebutuhan audit pemasaran pada UKM di Kota Malang dan pengembangan sebuah model konseptual berbasis konsep dan teori. Tahapan ini kemudian juga dilanjutkan dengan perancangan model aplikatif E-Marketing audit; dan 2) Pengukuran efektifitas dari penggunaan sistem.

Penelitian kualitatif yang sudah dilakukan adalah observasi untuk menggali pengukuran pengukuran yang dibutuhkan oleh sektor UKM, observasi dilakukan pada 20 pelaku UKM di Kota Malang sedangkan untuk mengelaborasi kebutuhan pengukuran marketing audit dilakukan depth in interview pada 3 pelaku usaha UKM terpilih yang memenuhi kriteria pengembangan sistem.

Tahapan penelitian selanjutnya adalah pengembangan sistem marketing audit, tahapan ini menggunakan model SDLC air terjun (waterfall), metode ini menyediakan pendekatan alur hidup perangkat lunak secara sekuensial atau urut dimulai dari analisis, desain, pengkodean, pengujian dan implementasi. Hasil desain yang dijadikan sebagai acuan dasar penyusunan sistem disusun Activity Diagram. Dalam tahapan ini ditentukan siapa saja yang dapat mengakses, 
dimensi ukuran audit yang akan dimunculkan, hasil akhir apa yang akan dimunculkan, desain sistem interaktif. Berikut ini gambaran Activity Diagram untuk Marketing Audit yang dikembangkan.

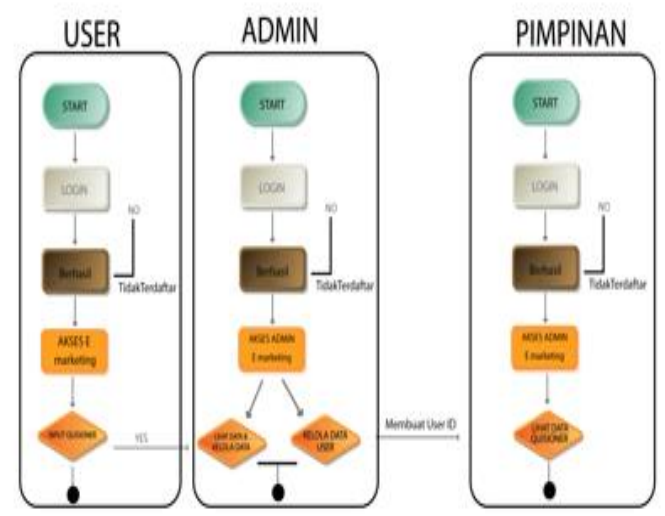

Gambar 2. Activity Diagram E-Marketing Audit

\section{HASIL DAN PEMBAHASAN}

Bidang kajian audit pemasaran tidak terlalu banyak dikaji, sehingga penelitian ini dilakukan untuk menyusun sebuah model yang sifatnya aplikatif. Beberapa penelitian empiris mengenai audit pemasaran pada perusahaan dalam rangka pengukuran performa bisnis dan penentu keunggulan bersaing telah dilakukan. Taghian dan Shaw (2008) melakukan penelitian terhadap 1.440 perusahaan yang pendapatannya tercatat dan dilaporkan di publik di Australia dari total 22.501 perusahaan. Bolisani dan Scarso (2012) mengembangkan marketing audit pada Knowledge-Intensive Business Services (KIBS). Sedangkan Brownlie (1993) mengembangkan bentuk tradisional marketing audit menggunakan checklist approach.

Model yang digagas pada penelitian ini dalam rangka mendukung penelitianpenelitian sebelumnya (Bolisani \& Scarso, 2012; Brownlie, 1993; Taghian \& Shaw, 2008). Kajian dari Öztamur \& Karakadilar (2014) terfokus mengkaji pengukuran performa bisnis pada SME yang menggunakan sosial media. Model ini juga meneruskan penelitian terdahulu dari Lestari dan Prihartono (2016) yang mengembangkan model audit pemasaran pada industri pendidikan dengan fokus audit pada bidang stratejik.

Sedangkan modifikasi model yang sesuai untuk sektor UKM didapatkan dari model yang dikembangkan oleh Yamani et al. (2019) yang mencoba menyusun penguatan teknologi informasi pada sektor UKM dalam rangka meningkatkan keunggulan UKM. Penelitian sejenis juga dilakukan Hasibuan (2015) dengan mengukur kinerja UKM bidang snack di Provinsi Banten dengan menggunakan performance profile analysis and development strategy of SMEs for snacks dan analisis SWOT untuk mengetahui kekuatan, kelemahan, peluang dan ancaman dari pelaku usaha bidang snack.

Kebaruan yang dihasilkan penelitian ini adalah mengelaborasi audit pemasaran dari komponen marketing function dengan dimensi pengukuran melalui marketing mix, serta mengembangkan pengukuran tersebut dalam bentuk applied berupa pengembangan pengukuran berbasis web yang dapat diakses secara langsung oleh pelaku usaha.

Berdasarkan hasil observasi dan Survei pada 20 pelaku UKM di Kota Malang yang terpilih, sebagian besar UKM tersebut sudah mulai menggunakan data sistem informasi dalam memproses hasil pemasaran usaha. UKM yang telah menggunakan sistem informasi merupakan target sasaran dalam pemberian feedback hasil pengembangan marketing audit selanjutnya. Pemilihan ini berdasarkan kapasitas pengetahuan dari pemilik UKM terkait pengelolaan data base dan sistem informasi. Sistem marketing audit yang dihasilkan terdiri dari dua bagian utama, yaitu bagian administratif untuk penginputan data dan bagian penampilan hasil audit, dimana ada 3 user yang dapat meng akses yaitu user atau pengguna, admin dan pimpinan.

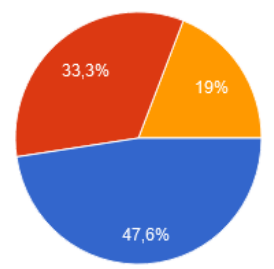

Sudah Belum

Gambar 3. UKM yang sudah Menggunakan Sistem Informasi 
Adapun Activity Diagram dari sistem ini dapat dilihat dari Gambar 1. Ketika ada transaksi penjualan barang/jasa, sistem ini dapat menginputkan data penjualan harian, atau sistem ini dapat mengimpor data dari kasir. Sistem ini dapat memilah varians produk mana yang paling disukai berdasarkan data penjualan. Sistem ini juga dapat menginputkan data perhitungan operasional, sehingga pemilik usaha dapat memperhitungkan harga yang harus dijual. Sistem ini didesain dapat melakukan audit saluran pemasaran serta audit kegiatan promosi perusahaan, sehingga pemilik usaha dapat memantau setiap rupiah yang telah dianggarkan untuk beriklan (baik manual ataupun menggunakan google ads/facebook ads/instagram) apakah memberikan eksposure dan impact pada peningkatan followers atau peningkatan jumlah pelanggan.

Sistem E-Marketing Audit merupakan sistem aplikasi audit pemsaran berbasis web. Sistem audit biasanya hanya digunakan oleh bidang keuangan.. Penelitian ini menerapkan sebuah teknologi berbasis web yang sangat mudah dan tidak rumit, karena penggunanya adalah pelaku usaha di sektor informal. Sistem ini adalah pengembangan teknologi dari model konseptual dari dari konsep beberapa peneliti sebelumnya (Bolisani \& Scarso, 2012; Hasibuan, 2015; Lestari \& Prihartono, 2016; Öztamur \& Karakadilar, 2014). Sistem ini dikembangkan dengan tahapan awal yatiu melakukan audit kegiatan fungsional pemasaran antara lain : produk, harga, keefektifan saluran distribusi (dalam hal ini dapat memantau apakah nantinya channel memasarkan menggunakan grab food atau go-food sangat efektif, serta audit kegiatan promosi. Sistem ini dapat mengakses dan mengaudit berapa besar expossure dari audiens terhadap akun sosial media dari UKM, dalam hal ini adalah mitra terpilih. Sistem ini dikembangkan secara konseptual pada tahun 2016 dan dilanjutkan pengembangan aplikasi berbasis web pada tahun 2020.

Hasil klaster penggolongan dimensi pengukuran marketing audit dari pelaku
UKM di Kota Malang dapat dilihat pada Tabel 1.

Tabel 1. Pengelompokan Ukuran Functional Marketing Audit UKM di Kota Malang

\begin{tabular}{|c|c|c|}
\hline Dimensi & Indikator Tertinggi & Persentase \\
\hline Variasi produk & $\begin{array}{l}\text { Variasi produk } \\
\text { paling banyak } \\
\text { disukai }\end{array}$ & $65 \%$ \\
\hline Feedback Produk & $\begin{array}{l}\text { Kualitas } \\
\text { produk/jasa }\end{array}$ & $85 \%$ \\
\hline $\begin{array}{l}\text { Ukuran Kekuatan } \\
\text { merek }\end{array}$ & $\begin{array}{l}\text { Banyaknya } \\
\text { pelanggan setia }\end{array}$ & $70 \%$ \\
\hline $\begin{array}{l}\text { Faktor terpenting } \\
\text { ukuran Kekuatan } \\
\text { Merek }\end{array}$ & $\begin{array}{l}\text { Komitmen } \\
\text { membeli kembali } \\
\text { (brand loyalty) }\end{array}$ & $50 \%$ \\
\hline $\begin{array}{l}\text { Audit Harga } \\
\text { Produk }\end{array}$ & $\begin{array}{l}\text { Kesesuaian harga } \\
\text { dengan kualitas }\end{array}$ & $50 \%$ \\
\hline $\begin{array}{l}\text { Audit Promosi yg } \\
\text { diharapkan }\end{array}$ & $\begin{array}{l}\text { Melalui iklan di } \\
\text { Instagram / Google } \\
\text { Ads/ FB Ads }\end{array}$ & $65 \%$ \\
\hline $\begin{array}{l}\text { Ukuran efektifitas } \\
\text { promosi }\end{array}$ & Peningkatan Omset & $50 \%$ \\
\hline $\begin{array}{l}\text { Ukuran efektifitas } \\
\text { saluran penjualan }\end{array}$ & $\begin{array}{l}\text { Menggunakan data } \\
\text { penjualan }\end{array}$ & $40 \%$ \\
\hline
\end{tabular}

Sumber : Olahan Data Peneliti, 2020

Berdasarkan kajian konseptual, model yang dijadikan rujukan serta pendalaman kebutuhan pengukuran marketing audit, maka disusun sistem marketing audit berbasis web dengan dimensi fungsional pemasaran. Adapun tampilan web dari sistem ini adalah sebagai berikut :

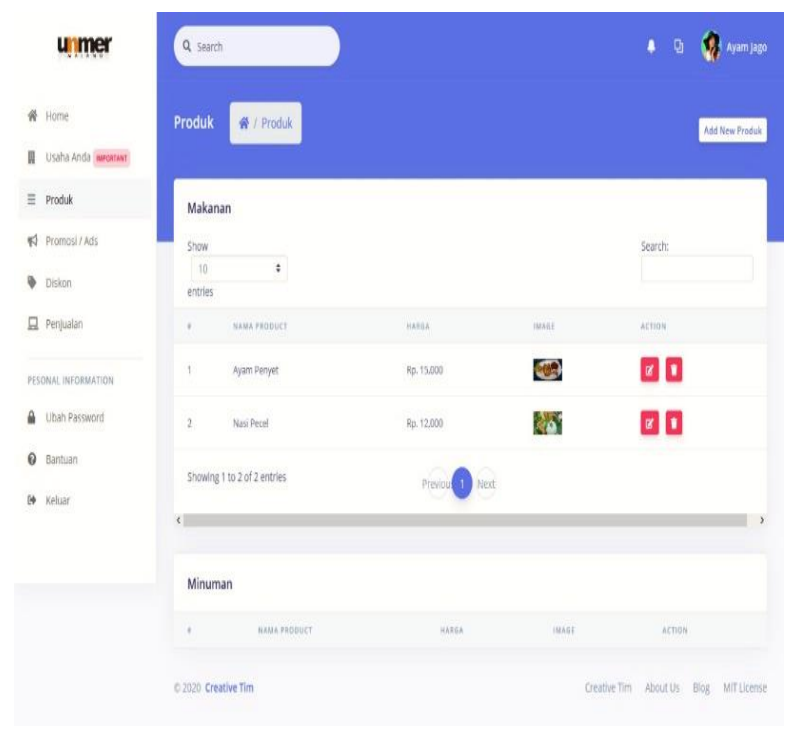

Gambar 4. Marketing Audit (Produk) 


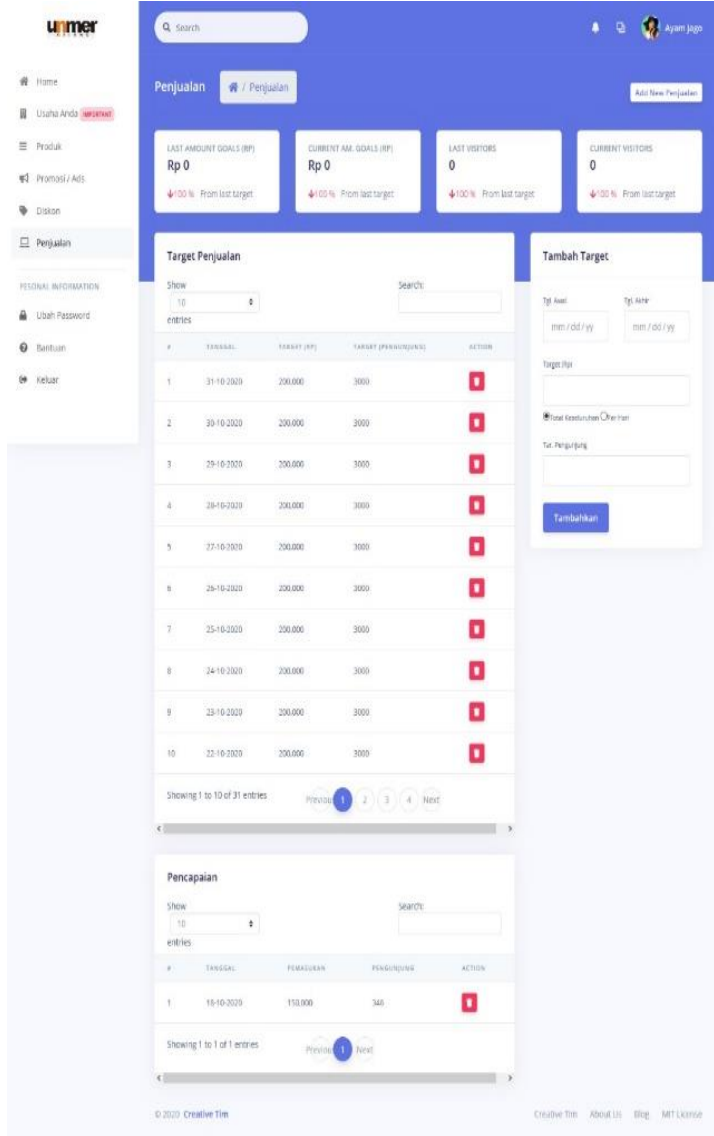

Gambar 5. Marketing Audit (Harga)

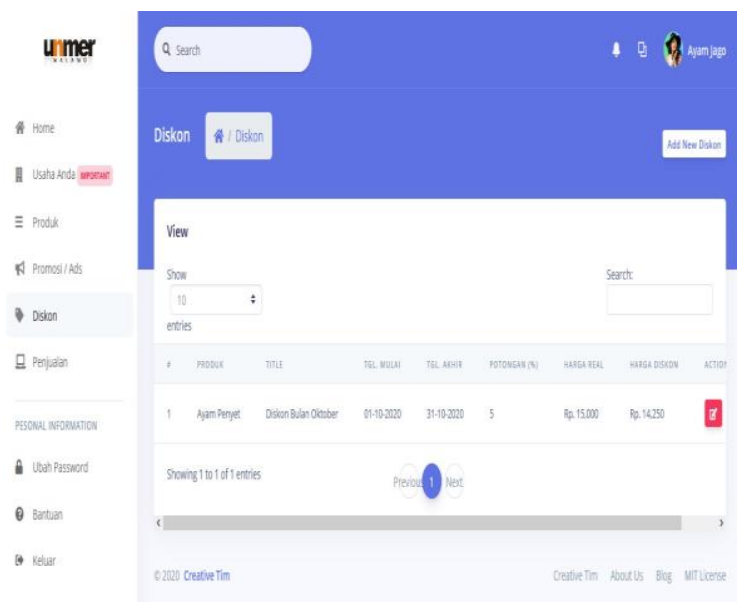

Gambar 6. Marketing Audit (Promosi)

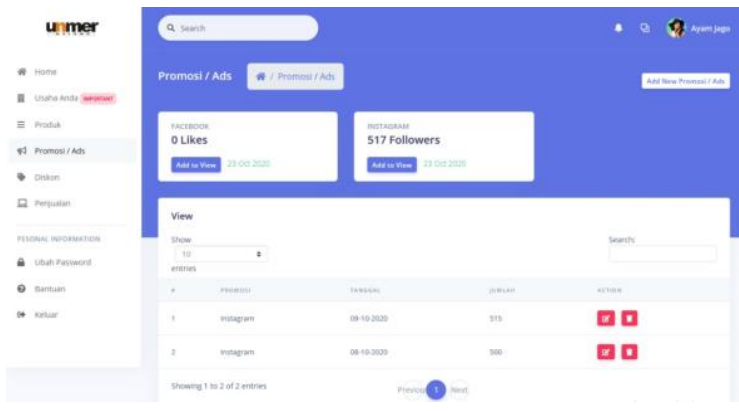

Gambar 7. Marketing Audit (Promosi Online)

\section{Kesimpulan}

Pengembangan sistem marketing audit merupakan metode self audit dengan fokus utama melakukan audit pada komponen marketing functions. Marketing function yang diukur dijabarkan menjadi beberapa dimensi berdasarkan pengelompokan tingkat kepentingan yang memiliki skor paling tinggi. Adapun ukuran-ukuran tersebut antara lain: pengukuran produk, pengukuran merek, pengukuran variasi produk, pengukuran harga berdasarkan data penjualan, pengukuran efektifitas promosi online dan pengukuran promosi berdasarkan data penjualan, pengukuran efektifitas saluran penjualan berdasarkan data penjualan. Ukuran-ukuran ini dirancang menggunakan sistem web dan di desain secara sederhana sehingga sistem ini dapat membantu UKM untuk melakukan pemantauan terhadap usahanya. Sistem ini juga dapat digunakan untuk melakukan pencatatan transaksi pembelian, transaksi penjualan, dan penghitungan laba kotor serta identifikasi atas laba yang belum direalisasi. Pengelolaan data data pemasaran (produk, harga, promosi, saluran penjulan) dengan memanfaatkan teknologi informasi yang berbentuk sistem marketing audit ini diharapkan dapat membantu UKM khususnya di Kota Malang untuk dapat mengintegrasikan data data dan memprosesnya menjadi sebuah informasi berharga mengenai performa bisnisnya.

Hasil penelitian ini berupa model dan sistem tentunya masih memiliki keterbatasan, karena hanya menjawab satu komponen pengukuran yaitu functional aspect. Masih terbuka peluang sistem ini dikembangkan lebih lanjut dengan melakukan pengukuran ukuran komponen-komponen marketing audit lainnya seperti lingkungan bisnis, strategi, sistem, dan produktivitas.

\section{DAFTAR PUSTAKA}

Aureli, S., \& Del Baldo, M. (2016). Peformance appraisal of business networks. how small and medium enterprises define and monitor network objectives. Management Control, (1), 35-58. 
https://doi.org/10.3280/maco2016001003

Bolisani, E., \& Scarso, E. (2012). Marketing audit for Knowledge Intensive Business Services. 12(1), 3-14.

Brownlie, D. (1996a). Marketing audits and auditing: Diagnosis through intervention. Journal of Marketing Management, 12(1-3), 99-112. https://doi.org/10.1080/0267257X.19 96.9964403

Brownlie, D. (1996b). The conduct of marketing audits a critical review and commentary. Industrial Marketing Management, 25(1), 11-22. https://doi.org/10.1016/00198501(95)00036-4

Brownlie, D. T. (1993). The marketing audit: A metrology and explanation. Marketing Intelligence \& Planning, 11(1), 4-12. https://doi.org/10.1108/02634509310 024128

Corsi K. (2006), I sistemi di indicatori di performance nelle piccole e medie imprese, In AaVv, Scritti in Onore di Isa Marchini (pp. 284-308), Milano, Franco Angeli.

Farneti G. \& Bartolini M. (2009), Sistemi di controllo manageriale e medie imprese. Un'indagine nella provincia di Forlì-Cesena, Milano, Franco Angeli.

Gibbs, Paul; Knapp, Michael. 2002. Marketing Higher and Further Education. Kogan Page.UK

Hasibuan, S. (2015). SMEs development strategy for competitive and sustainable typical local snacks of Banten Province. International Journal on Advanced Science, Engineering and Information Technology, 5(6), 410-414. https://doi.org/10.18517/ijaseit.5.6.60 2

Klinčeková, S., \& Šalgovičová, J. (2014). The role of marketing audit and value of information. International Journal for Innovation Education and Research, 2(01), 8-13.
Kotler, P. \& Armstrong, G. (2010). Principles of marketing.Peaeson education.USA

Kotler, P., Gregor, W. \& Rodgers, W. (1977) The marketing audit comes of age. Sloan Management Review. 18(Winter), 25-44.

Lombardi, R., Caputo A., Russo, G. \& Formisano V. (2015), Management control of contractual networks, International Journal of Applied Management Science, 7(4), pp. 269286.

Lestari, R., \& Prihartono AH. (2016). International Conference on Economics, Business and Social Sciences (ICEBUSS 2016). International Conference on Economics, Business and Social Sciences (ICEBUSS 2016), 1, 96. Malang: Faculty of Economics University of Islam Malang.

Öztamur, D., \& Karakadılar, İ. S. (2014). Exploring the role of social media for smes: as a new marketing strategy tool for the firm performance perspective. Procedia-Social and Behavioral Sciences, 150, 511-520. https://doi.org/10.1016/j.sbspro.2014. 09.067

Pontoh, W., \& Budiarso, N. S. (2020). IPTEKS Sistem Informasi Sederhana Atas Manajemen. 05(01), 8-20.

Taghian, M. \& Shaw, R. N. (2002). The Marketing Audit and Business Performance: An Empirical Study of Large Australian Companies. ANZMAC Conference Proceedings

Taghian, M., \& Shaw, R. N. (2008). The marketing audit and organizational performance: An empirical profiling. Journal of Marketing Theory and Practice, 16(4), 341-350. https://doi.org/10.2753/MTP10696679160406

Wirda, F., Herri, Elfindri, Rivai, H. A., \& Herizon. (2019). Competitive advantage: Mediation effect between entrepreneurial competency and business performance creative industries in West Sumatera- 
Indonesia. Academy of

Entrepreneurship Journal, 25(1), 111.

Yamani, A. Z., Muhammad, A. W., \& Faiz, M. N. (2019). Penguatan Ekonomi Lokal Pada Pelaku UMKM Berbasis Digital Di Desa Winduaji Kabupaten Brebes. Madani : Indonesian Journal of Civil Society, 1(1), 24-28. https://doi.org/10.35970/madani.v1i1. 29 